\title{
Answer to the Letter to the Editor of J.M. Duart Clemente et al. concerning "multilevel oblique corpectomy for cervical spondylotic myelopathy preserves segmental motion" by AG Chacko, M Joseph, MK Turel, K Prabhu, RT Daniel, KS Jacob (2012) Eur Spine J. 2012;21(7):1360-1367
}

\author{
Ari George Chacko - Mathew Joseph • \\ Mazda Keki Turel • Krishna Prabhu • \\ Roy Thomas Daniel • K. S. Jacob
}

Received: 7 July 2013/Published online: 24 July 2013

(C) Springer-Verlag Berlin Heidelberg 2013

We thank J.M. Duart Clemente et al. for their interest in our article and raising important issues. Interestingly, the incidence of preoperative neck pain was low in our series despite this being a younger cohort of patients without degenerated and fused spines. In addition, neck pain was not a complaint noted during the follow-up period though we have not presented this in the results. We agree that the main goal of surgery is decompression for neurological improvement and not motion preservation. Ours was a unique group of younger patients with soft discs that stands in contrast to the older set of patients with degenerated and largely fused spines reported in Western series [1]. Having performed the oblique corpectomy with good outcomes, we noted the preservation of motion in the short term as a secondary finding that has not been reported previously with this technique. We have also documented a reduction in cervical motion with longer follow-up indicating that the body tends to fuse the spine with production of anterior osteophytes in this relentlessly progressive degenerative disease [2]. Furthermore, the analysis of data from our consecutive series of 153 patients demonstrated that the neurological function and thereby functional outcome was markedly improved following oblique corpectomy. This improved status remained without secondary worsening on long-term follow-up [3]. The technique of oblique corpectomy ensures the removal of the entire posterior surfaces of the affected vertebrae compressing the cord at presentation. The subsequent "cervicoarthrosis" that could reform on the long term are predominantly at the anterior surfaces of the vertebrae and cannot, therefore, endanger the decompressed spinal cord. This would explain the lack of progressive neurological deterioration at least due to a compressive element at the segments treated. We agree wholeheartedly that although motion preservation is not the primary objective of this surgery, we could avoid or at least retard the development of adjacent segment disease. Longterm follow-up is, of course, mandatory to ensure that these patients do not develop progressive kyphosis or adjacent segment disease.

Conflict of interest None.

\section{References}

1. Chibbaro S, Mirone G, Makiese O, George B (2009) Multilevel oblique corpectomy without fusion in managing cervical myelopathy: long-term outcome and stability evaluation in 268 patients. J Neurosurg Spine 10(5):458-465

2. Turel MK, Sarkar S, Prabhu K, Daniel RT, Jacob KS, Chacko AG (2013) Reduction in range of cervical motion on serial long-term follow-up in patients undergoing oblique corpectomy for cervical spondylotic myelopathy. Eur Spine J; Mar 2013 [Epub ahead of print]

3. Chacko AG, Turel MK, Sarkar S, Prabhu K, Daniel RT (2013) Clinical and radiological outcomes in 153 patients undergoing oblique corpectomy for cervical spondylotic myelopathy. Br J Neurosurg (In press)
A. G. Chacko $(\bowtie) \cdot$ M. Joseph · M. K. Turel · K. Prabhu ·

R. T. Daniel - K. S. Jacob

Department of Neurological Sciences, Christian Medical

College, Vellore 632004, India

e-mail: agchacko@cmcvellore.ac.in 